\title{
MINIREVIEW
}

\section{Schizophrenic: forever young?}

\author{
Benedetta Frida Baldi ${ }^{\dagger}$, Christine Hoyer ${ }^{\dagger}$ and Nicolas Le Novère*
}

\begin{abstract}
Schizophrenia is a multifactorial complex disease with a large impact on society. Many hypotheses have been proposed over the years to explain its causes, and genomics and functional genomic approaches may shed light on the reason behind these controversies and discrepancies. We give an overview of several approaches that have been used to identify the genetic causes and molecular phenotypes of the disease. We focus on a recent microarray analysis by Torkamani and colleagues on the evolution of regulatory networks in normal and schizophrenic brains. Combining the conclusion of that study with the prevalent hypotheses of schizophrenia, we suggest that the schizophrenic brain might resemble a juvenile brain.
\end{abstract}

\section{Introduction}

Schizophrenia is a severe psychiatric disorder that has a predicted prevalence of about $0.5 \%$ in the population worldwide [1]. Although it has provided geniuses such as the mathematician John Forbes Nash and the dancer Vaslav Nijinsky, the disease is debilitating and it is a significant social burden. The direct costs of treatment and care associated with schizophrenia in England alone for the year 2005 were about two billion pounds. The cost for informal and private care for families was $£ 615,000,000$, indicating a significant impact of the disease on society [2].

Since its description as a distinct syndrome affecting teenagers and young adults, termed démence précoce (literally 'early dementia'), by Bénédict Morel in 1853, schizophrenia has been associated with a heterogeneity of symptoms that have made its identification problematic. Emile Kraepelin was one of the first to characterize it in 1887, dividing it into four categories: 'simple', 'paranoid,' 'hebephrenic' and 'catatonic.' Schizophrenia

${ }^{+}$Contributed equally

*Correspondence: lenov@ebi.ac.uk

European Bioinformatics Institute, Wellcome Trust Genome Campus, Hinxton, Cambridgeshire CB10 1SD, UK got its current name in 1908 from Eugen Bleuler, who classified the symptoms into the so-called four 'A's categories: blunted 'affect', loosening of 'associations', 'ambivalence' and 'autism. Modern diagnosis of schizophrenia is based on the World Health Organization classification (ICD-10) [3] or the Diagnostic and Statistical Manual of Mental Disorders (DSM-IV) [4]. These classifications are grounded in the classification provided by Kurt Schneider in 1959, with no direct correlation between symptoms and physiological evidence of the disease [5]. A revision of the characteristic symptoms and classification of schizophrenia is now in progress, and DSM-V will be published in 2013. However, diagnosis will still rely on the subjective judgment of a patient's behavior and experience, aided by the observed response to drug treatment as an additional indicator. The symptoms of schizophrenia are classified in two different categories: positive and negative. Some of the most frequently positive symptoms are delusions, hallucinations and reality distortions, whereas loss of motivation, poverty of speech, apathy and reduced social drive belong to the negative manifestations of the disease.

Many hypotheses have been formulated to explain the symptoms of schizophrenia. Due to the ability of several neuroleptic drugs, such as haloperidol, to mitigate positive symptoms, the implication of deregulation in dopamine transmission was widely studied and led to the postulation of the hyperdopaminergic hypothesis of schizophrenia [6]. Meanwhile, studies of use or abuse of phenclyclidine or ketamine, which are $N$-methyl-Daspartate receptor antagonists, revealed the possible implication of glutamatergic transmission in the pathology of the disorder [7]. These drugs can produce schizophrenic-like positive and negative symptoms in healthy individuals and severely aggravate the symptoms of patients with schizophrenia [8,9]. More recently, schizophrenia was postulated to be a neurodevelopmental disorder. Deregulation of brain development in early childhood and adolescence is thought to lead to structural and functional disconnectivity that causes the symptoms of schizophrenia [10]. As for many multifactorial complex diseases, conceptualization is hampered by the confusion between the pathogenesis, the causes of the disease, and the symptomatology, with the symptoms resulting from the disease. The distinction between the 
two domains became even more blurred with the advent of functional genomics.

\section{Pathogenesis}

Although environmental risk factors play a role in the progress of schizophrenia, there seems to be a strong heritable component for the development of the disease, as observed in twin studies [11] and in high-incidence families [12]. Knowledge of the susceptibility genes could improve the treatment of patients by allowing earlier intervention through treatment, increasing the chances of alleviating the symptoms or even recovery. To date, many genomic studies, such as linkage analysis, genome association, genome-wide analysis of single nucleotide polymorphism and copy number variations, have tried to investigate the genetic origin of schizophrenia, without clear-cut results. Using the genetic information from families with a high incidence for the disease, candidate chromosomal regions have been identified [13,14]. Single nucleotide polymorphism analysis, which for other diseases such as Parkinson's disease or Alzheimer's disease has clearly highlighted interesting candidate genes, has shown ambiguous results for schizophrenia. Nevertheless, different gene sets have been highlighted, including $E R B B 4$, major histocompatibility complex (MHC) class I and II [15], COMT [16] and DISC1 [17], although the data appear to lack reproducibility. This may be due to the susceptibility of these approaches to false-positive results. Additionally, the phenotypic heterogeneity of schizophrenia could also be the result of a heterogeneous pathogenotype diluting signals of single interesting genes in genome-wide studies.

\section{Molecular symptomatology}

In addition to genomic studies, transcriptomic [18] and proteomic [19] approaches have been used, producing sets of candidate genes that are not necessarily congruent with other studies. Moreover, in the analysis of data from divergent sources, we must bear in mind that medical treatment can cause severe differences in protein production levels and tissue organization [20]. Cause of death, handling and sample preparation must also be taken into account. Although it is difficult to name specific genes or proteins that are involved in the development of the disease, some biological functions seem to play a particularly important role, such as certain cell signaling pathways, synaptic transmission, energy metabolism with a particular focus on mitochondrial protein, and oxidative stress damage [21]. Recently, a coexpression network analysis was performed by Torkamani and colleagues [22] using microarray expression data from postmortem brain samples. The study included 47 patients with schizophrenia (diagnosis based on DSM-IV criteria) and 54 healthy controls, with an age range of 19 to 81 years. They used the ARACNE algorithm, which is an information theoretic approach [23], on the microarray expression profiles to determine the underlying regulatory network topology and identify regulatory modules therein using hierarchical clustering. This analysis emphasized that schizophrenia might not be the result of just a few highly deregulated candidate genes. It suggested that the overall regulatory structure in the schizophrenic brain is kept intact, while subtle deregulations occur within certain identified regulatory modules. Gene ontology enrichment studies relate those affected modules to typical neuronal functions. The study addressed not only the differential gene regulation between cases and controls, but also the developmental and degenerative nature of schizophrenia, taking into account the age of each subject. Analysis of the data also highlighted modules that might be differentially expressed, dependent on age, in healthy and diseased subjects.

\section{A schizophrenic brain might resemble a juvenile brain}

Torkamani and colleagues identified sets of genes that showed age-dependent regulation in patients, but not in healthy subjects, including genes functionally related to chromosome organization, the cell cycle, DNA damage repair, transport processes, lipid metabolism, neuronal regeneration and neurogenesis. Conversely, the agerelated downregulation of genes in modules associated with developmental processes such as neuronal differentiation, neurite outgrowth and synaptic transmission appeared to be absent in patients with schizophrenia. These findings lend weight to the neurodevelopmental hypothesis of schizophrenia. A recent imaging study showed that one of the prominent phenotypical properties of the schizophrenic brain is an abnormal development of grey matter [24]. Grey matter density in patients with schizophrenia peaks during adolescence, and then it decreases faster than in healthy individuals. The healthy group displays a continuous decrease from early adolescence onwards, and this slows down during adulthood. This difference reflects the progressive character of the disease, and might be related to the groups of age-dependent genes deregulated in patients. A component of the disease seems to be abnormal development of the brain, which is blocked in a juvenile stage, as suggested by the modules that fail to be downregulated in patients with schizophrenia. Among the genes involved is the gene encoding dopamine D1 receptor, which is usually downregulated during aging, and is foremost in cortical and caudate regions in normal individuals [25]. Included in the dataset studied by Torkamani and colleagues was COMT (the gene encoding catechol-O-methyl transferase), which is another gene 
related to dopamine signaling that has previously been implicated in the development of schizophrenia. COMT is part of the differentially regulated modules that are age independent. The hyperactive state of the dopamine system in a patient with schizophrenia resembles the dopamine hyperactivity in the brain of an adolescent [26], and it might show how a regulatory feature that might be beneficial during a certain life stage (at least on a population based scale) could result in a psychiatric disease if proper shutdown of the system fails. Unfortunately, the dopamine D2 receptor, upon which the dopamine hypothesis of schizophrenia was originally based, was not present in the dataset studied by Torkamani and colleagues. The glutamate system in the brain of patients is also affected. The number of glutamatergic synapses peaks during early childhood in healthy individuals, and subsequently decreases with rapid decline during adolescence [27]. In the schizophrenic brain, this mechanism fails, again indicating that the brain is stuck in an adolescent developmental stage.

\section{Conclusions}

A major issue today lies in the diagnosis of schizophrenia because of its very broad symptomatic range. This is also reflected in the outcome of genomic and proteomic studies. Many of the candidate genes that have been identified are shared with other mental disorders. Schizophrenia might not be a single disease with a distinct and clear pathogenesis, but rather a sum of different subtle genetic deregulations. The subset of these deregulations present in each individual could account for the heterogeneity of the observed different psychotic phenotypes. Small-scale analyses, such as family studies, tend to associate single genetic variations with a disease. These variations could be a major risk factor for that family, but might not cause the disease when put into another genetic background, and this is where large-scale analyses come into play. In a sufficiently large dataset, the effect of emphasizing single variations is averaged out and allows the analysis of biological pathways instead of single genes, as presented in the paper by Torkamani et al. When sufficient data become available, quantitative computational systems biology could provide kinetic models that aid in understanding the nature of the deregulations present in the pathways of the schizophrenic brain. This would allow the identification of a set of network nodes that could be targeted in a combined drug therapy. A polypharmacology approach, where multiple targets are taken into account at the same time, could help the network to restore a healthy state.

One of the issues to be addressed in schizophrenia research is the standardization of protocols and the minimum amount of information required for a study. Examples in various fields have been gathered under the umbrella of the Minimum Information for Biological and Biomedical Investigations project [28]. Especially in schizophrenia research, it is necessary to provide the history of drug treatment, the cause of death and the age of a sample, as well as environmental factors that might have influenced development of the disease. A rigorous statistical approach to the data and its clear declaration should also be included. It is also advisable to provide general access to the data and analyses to enable comparisons between studies, interpretation of results, and meta analyses.

\section{Competing interests}

The authors declare that they have no competing interests.

\section{Authors' contributions}

Each author contributed to the manuscript. BFB and $\mathrm{CH}$ made equal contributions.

\section{Acknowledgements}

We thank Nick Juty for proofreading the manuscript, and Mike Croning and Louie van de Laagemaat for useful discussions.

Published: 18 May 2010

\section{References}

1. Goldner EM, Hsu L, Waraich P, Somers JM: Prevalence and incidence studies of schizophrenic disorders: a systematic review of the literature. Can J Psychiatry 2002, 47:833-843.

2. Mangalore R, Knapp M: Cost of schizophrenia in England. J Ment Health Policy Econ 2007, 10:23-41.

3. World Health Organization: The ICD-10 Classification of Mental and Behavioural Disorders - Diagnostic Criteria for Research. Geneva: World Health Organization; 1993.

4. American Psychiatric Association: Diagnostic and Statistical Manual of Mental Disorders. Washington, DC: American Psychiatric Association; 2000.

5. Schneider K: Clinical Psychopathology. 5th edition. New York: Grune and Stratton; 1959.

6. Seeman P: Dopamine receptors and the dopamine hypothesis of schizophrenia. Synapse 1987, 1:133-152.

7. Olney JW, Newcomer JW, Farber NB: NMDA receptor hypofunction model of schizophrenia.J Psychiatr Res 1999, 33:523-533.

8. Javitt DC, Zukin SR: Recent advances in the phencyclidine model of schizophrenia. Am J Psychiatry 1991, 148:1301-1308.

9. Krystal JH, Karper LP, Seibyl JP, Freeman GK, Delaney R, Bremner JD, Heninger GR, Bowers MB, Charney DS: Subanesthetic effects of the noncompetitive NMDA antagonist, ketamine, in humans. Psychotomimetic, perceptual, cognitive, and neuroendocrine responses. Arch Gen Psychiatry 1994, 51:199-214.

10. Karlsgodt KH, Sun D, Jimenez AM, Lutkenhoff ES, Willhite R, van Erp TGM Cannon TD: Developmental disruptions in neural connectivity in the pathophysiology of schizophrenia. Dev Psychopathol 2008, 20:1297-1327.

11. Sullivan PF, Kendler KS, Neale MC: Schizophrenia as a complex trait: evidence from a meta-analysis of twin studies. Arch Gen Psychiatry 2003, 60:1187-1192.

12. Brandon NJ, Millar JK, Korth C, Sive H, Singh KK, Sawa A: Understanding the role of DISC1 in psychiatric disease and during normal development. J Neurosci 2009, 29:12768-12775.

13. Badner JA, Gershon ES: Meta-analysis of whole-genome linkage scans of bipolar disorder and schizophrenia. Mol Psychiatry 2002, 7:405-411.

14. Lewis CM, Levinson DF, Wise LH, DeLisi LE, Straub RE, Hovatta I, Williams NM, Schwab SG, Pulver AE, Faraone SV, Brzustowicz LM, Kaufmann CA, Garver DL, Gurling HMD, Lindholm E, Coon H, Moises HW, Byerley W, Shaw SH, Mesen A, Sherrington R, O'Neill FA, Walsh D, Kendler KS, Ekelund J, Paunio T, Loennqvist $J$, Peltonen L, O'Donovan MC, Owen MJ, et al: Genome scan meta-analysis of schizophrenia and bipolar disorder, part II: schizophrenia. Am J Hum Genet 2003, 73:34-48.

15. Shi J, Levinson DF, Duan J, Sanders AR, Zheng Y, Pe'er I, Dudbridge F, Holmans 
PA, Whittemore AS, Mowry BJ, Olincy A, Amin F, Cloninger CR, Silverman JM, Buccola NG, Byerley WF, Black DW, Crowe RR, Oksenberg JR, Mirel DB, Kendler KS, Freedman R, Gejman PV: Common variants on chromosome 6p22.1 are associated with schizophrenia. Nature 2009, 460:753-757.

16. Shifman S, Bronstein M, Sternfeld M, Pisant'e-Shalom A, Lev-Lehman E, Weizman A, Reznik I, Spivak B, Grisaru N, Karp L, Schiffer R, Kotler M, Strous RD, Swartz-Vanetik M, Knobler HY, Shinar E, Beckmann JS, Yakir B, Risch N, Zak NB, Darvasi A: A highly significant association between a COMT haplotype and schizophrenia. Am J Hum Genet 2002, 71:1296-1302.

17. Mackie S, Millar JK, Porteous DJ: Role of DISC1 in neural development and schizophrenia. Curr Opin Neurobiol 2007, 17:95-102.

18. Konradi C: Gene expression microarray studies in polygenic psychiatric disorders: applications and data analysis. Brain Res Brain Res Rev 2005, 50:142-155.

19. Martins-De-Souza D, Dias-Neto E, Schmitt A, Falkai P, Gormanns P, Maccarrone G, Turck CW, Gattaz WF: Proteome analysis of schizophrenia brain tissue. World J Biol Psychiatry 2010, 11:110-120.

20. Lieberman JA, Bymaster FP, Meltzer HY, Deutch AY, Duncan GE, Marx CE, Aprille JR, Dwyer DS, Li XM, Mahadik SP, Duman RS, Porter JH, ModicaNapolitano JS, Newton SS, Csernansky JG: Antipsychotic drugs: comparison in animal models of efficacy, neurotransmitter regulation, and neuroprotection. Pharmacol Rev 2008, 60:358-403.

21. Prabakaran S, Swatton JE, Ryan MM, Huffaker SJ, Huang JTJ, Griffin JL, Wayland M, Freeman T, Dudbridge F, Lilley KS, Karp NA, Hester S, Tkachev D, Mimmack ML, Yolken RH, Webster MJ, Torrey EF, Bahn S: Mitochondrial dysfunction in schizophrenia: evidence for compromised brain metabolism and oxidative stress. Mol Psychiatry 2004, 9:684-97, 643.

22. Torkamani A, Dean B, Schork NJ, Thomas EA: Coexpression network analysis of neural tissue reveals perturbations in developmental processes in schizophrenia. Genome Res 2010, 20:403-412.

23. Margolin AA, Nemenman I, Basso K, Wiggins C, Stolovitzky G, Dalla Favera R,
Califano A: ARACNE: an algorithm for the reconstruction of gene regulatory networks in a mammalian cellular context. BMC Bioinformatics 2006, 7(Suppl 1):S7.

24. Douaud G, Mackay C, Andersson J, James S, Quested D, Ray MK, Connell J, Roberts N, Crow TJ, Matthews PM, Smith S, James A: Schizophrenia delays and alters maturation of the brain in adolescence. Brain 2009, 132:2437-2448

25. Jucaite A, Forssberg H, Karlsson P, Halldin C, Farde L: Age-related reduction in dopamine D1 receptors in the human brain: from late childhood to adulthood, a positron emission tomography study. Neuroscience 2010, 167:104-110.

26. Wahlstrom $D$, White T, Luciana M: Neurobehavioral evidence for changes in dopamine system activity during adolescence. Neurosci Biobehav Rev 2010, 34:631-648.

27. Jaaro-Peled H, Hayashi-Takagi A, Seshadri S, Kamiya A, Brandon NJ, Sawa A: Neurodevelopmental mechanisms of schizophrenia: understanding disturbed postnatal brain maturation through neuregulin-1-ErbB4 and DISC1. Trends Neurosci 2009, 32:485-495.

28. Taylor CF, Field D, Sansone SA, Aerts J, Apweiler R, Ashburner M, Ball CA, Binz PA, Bogue M, Booth T, Brazma A, Brinkman RR, Michael Clark A, Deutsch EW, Fiehn O, Fostel J, Ghazal P, Gibson F, Gray T, Grimes G, Hancock JM, Hardy NW, Hermjakob H, Julian RK Jr, Kane M, Kettner C, Kinsinger C, Kolker E, Kuiper M, Le Novère $N$, et al: Promoting coherent minimum reporting guidelines for biological and biomedical investigations: the MIBBI project. Nat Biotechnol 2008, 26:889-896.

doi:10.1186/gm153

Cite this article as: Frida Baldi B, et al.: Schizophrenic: forever young?

Genome Medicine 2010, 2:32. 